\title{
Clinical Consequences and Economic Burden Associated with Febrile Neutropenia in Hospitalized Cancer Patients: A Prospective Study
}

\author{
Tamanna Bahar ${ }^{1 *}$, Shaila Rahman ${ }^{2}$, Zulfia Zinat Chowdhury ${ }^{1}$, Tania Kabir ${ }^{3}$, Fahmida Akther ${ }^{4}$, Salina Haque ${ }^{1}$, AKM
} Mynul Islam ${ }^{1}$, Mohammad Ali ${ }^{1}$, Md. Mahbubur Rahman ${ }^{1}$

\begin{abstract}
Objective: Febrile neutropenia (FN) is viewed as the most decimating oncological crisis particularly in chemotherapy-incited patients. The primary objective of the study was to identify the total direct expenditure of patients during febrile neutropenia with clinical consequences and the secondary aim was to find out the factors associated with higher cost.

Materials and Method: This was a single-centered hospital-based study in the largest and only specialized cancer care centre in Bangladesh in the government sector. This prospective study was done in the inpatients' department of the National Institute of Cancer Research and Hospital from April 2020 to January 202I. The primary outcome was the out-of-pocket patient payments (adjusted by government subsidy) per FN episode. Univariate analysis and multiple linear regression were conducted to identify the factors associated with higher costs.

Results and Discussions: $A$ total of 101 patients were enrolled in the study. The mean (SD) age was 33.49 ( \pm 15.79 ) years. Of the 101 participants, $63.4 \%$ were male.Among the patients, $13.9 \%$ died during the episode and $86.1 \%$ recovered. Having co-morbidities and COVID-19 were associated with an increased risk of death. The mean cost was US\$ 999.44 ( \pm 499.05$)$ and the mean length of hospital stay was 21.98 ( \pm 9.3$)$ days. The longer hospital stay was significantly associated with higher costs.

Conclusion: This study will help to ascertain the hospital cost and clinical outcome of FN which ultimately can help in policymaking strategy.

Key words: Febrile neutropenia, economic burden, consequence, oncological emergency.

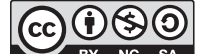

DOI: https://doi.org//0.3329/jom.v23il.57937 Copyright: (C) 2022 Bahar T. This is an open access article published under the Creative Commons Attribution-NonCommercial-NoDerivatives 4.0 International License, which permits use, distribution and reproduction in any medium, provided the original work is properly cited, is not changed in any way and it is not used for commercial purposes.
\end{abstract}

Received: 20 May, 202I;

Accepted: 13, November, 2021

\section{Introduction:}

Febrile neutropenia (FN) is an oncological emergency that needs to be addressed and managed promptly and properly. ${ }^{1}$ $\mathrm{FN}$ is defined as a single oral temperature of $\geq 38.3^{\circ} \mathrm{C}\left(101^{\circ} \mathrm{F}\right)$ or a temperature of $\geq 38.0^{\circ} \mathrm{C}\left(100.4^{\circ} \mathrm{F}\right)$ sustained for one

1. Department of Haematology, National Institute of Cancer Research and Hospital, Dhaka, Bangladesh.

2. Department of Medicine, Enam Medical College \& Hospital, Dhaka, Bangladesh.

3. Bangladesh Secretariat Clinic,Dhaka,Bangladesh.

4. Deapartment of Medicine,Jalalabad Ragib Rabeya Medical College and Hospital,Sylhet,Bangladesh.

*Corresponding author: *Tamanna Bahar, Department of Haematology, National Institute of Cancer Research and Hospital, Dhaka, Bangladesh. Email: tamanna.bahar@yahoo.com hour. ${ }^{2,3}$ Neutropenia is defined as an absolute neutrophil count $<1,000 / \mu \mathrm{L}$ (equivalent to $<1.0 \times 10^{9} / \mathrm{L}$ ), severe neutropenia as absolute neutrophil count $<500 / \mu \mathrm{L}$ (equivalent to $<0.5 \times 10^{9} / \mathrm{L}$ ), and profound neutropenia as $<100 / \mu \mathrm{L}$ (equivalent to $<0.1 \times 10^{9} / \mathrm{L}$ ). The period of neutropenia is considered protracted if it lasts for seven days or longer. ${ }^{4,5}$

Neutropenia and subsequent infections cause a large number of mortality and morbidity in cancer patients. A study from Singapore showed that the inpatient mortality rate of FN is between $4.7 \%$ and $9.5 \%{ }^{3,6} \mathrm{FN}$ frequently leads to a chemotherapy dose reduction and to treatment delays, which subsequently affect the patients' long-term clinical outcomes. ${ }^{3,7}$ 
Apart from clinical adversity, FN causes a significant economic burden, especially in hospitalized patients. $80 \%$ of patients with haematological malignancies suffer from $\mathrm{FN}^{8}$. Many research has been conducted worldwide to correlate the cost-affecting factors with total hospital cost. One study from the USA revealed that the average costs of FN in hospitalized patients ranged from US\$18,880 to US\$22,086. The costs for outpatient were lower than that of inpatient care. ${ }^{9}$ A prospective study from Germany showed the estimated mean direct cost per FN episode requiring hospital care was $\bullet 3,950 .{ }^{10,11,12} \mathrm{~A}$ study from Singapore revealed that the mean out-of-pocket patient payment was US\$2,230 per FN episode. ${ }^{3}$

No specific data were found regarding the mortality and economic burden of patients due to FN in Bangladesh. These types of studies are therefore needed to be done on a large scale to estimate the accurate cost associated with various types of tumor which ultimately will help in policymaking. This prospective study aimed to find out the out-of-pocket expenditure, the factors associated with higher costs, and mortality due to FN in a single episode in hospitalized patients. This study will help to lower future costs. By identifying the risk factor associated with mortality will help us to be more cautious while treating patients with FN and ultimately reducing death.

\section{Methods}

Study design and setting

A prospective study was conducted in the inpatients' department of National Institute of Cancer Research and Hospital, Dhaka, Bangladesh from April 2020 to January 2021. 101 patients with neutropenic fever were enrolled in this study.

\section{Patient population}

Patients aged $\geq 13$ years were included in the study who received chemotherapy for the treatment of haematological malignancies and developed febrile neutropenia. In patients who experienced multiple episodes of FN during the study period, the first episode was selected for analysis. Outdoor patients and neutropenia due to causes other than chemotherapy were excluded from the study. Clinical data (demographic, medical history, medications history, and treatment outcome) and the cost out-of-pocket patient payments were obtained prospectively from patients. The patients were hospitalized till full recovery from low ANC and fever.

The expenditure was estimated from the patients which included the total hospital cost, the reimbursement bill, the out-of-pocket patient payments, and the cost breakdown of out-of-pocket patient payments (consisting of ward charges, food charges, laboratory charges, radiology charges, medicine charges, and other charges). The government subsidizes charges mainly for chemotherapy drugs, antibiotics, room charges but total government charges could not be established properly. The costs associated with the treatment of underlying cancer were not included.

The primary outcome of the study was the out-of-pocket patient payments per $\mathrm{FN}$ episode. Univariate and multivariate analyses were performed to identify the factors which had significant associations with a higher cost per FN episode. We evaluated the demographics (age and gender), malignancy types, co-morbidities, days of onset of FN, length of stay (LOS) in hospital, use of stimulators (GCSF and pegylated interferon), and the responsiveness to treatment.

The clinical and demographic characteristics were reported for each patient based on a single admission per patient.

\section{Statistical analysis}

We evaluated all of the FN-associated admissions in the hospital. Descriptive analyses were used to summarize the primary study outcome of the study. The means and 95\% confidence intervals (CI) were reported. Group comparisons of parametric data were conducted using the Student's ttest or analysis of variance (ANOVA). Scheffe's test with Bonferroni correction was performed if there was a statistically significant finding through the ANOVA test. This step was performed to identify the variables of interest which may affect the outcome of this study. Pearson's correlation coefficient analysis was conducted to identify the variables significantly associated with a higher total hospital cost or out-of-pocket patient payments. After identifying the variables which were significantly associated with higher costs, multiple linear regression models were conducted to estimate the out-of-pocket patient payments. IBM SPSS Statistics 25.0 was used for all of the statistical analyses.

\section{Results}

A total of 101 patients with FN completed the study. The mean age was $33.49( \pm 15.79)$. Of the 101 participants, $63.4 \%$ were male. The most common haematological malignancy was acute lymphoblastic leukaemia (ALL) followed by acute myeloblastic leukaemia (AML), non-Hodgkin's (NHL), and Hodgkin's lymphoma (HL). Only 7 (6.9\%) of the study participants had co-morbidities of which diabetes mellitus and ischaemic heart disease (IHD) were the most common ones. Microbiologically documented infection was found in seven (7\%) patients. Klebsiella pneumoniae (2), Escherichia coli (3), Rhizobium radiobacter (1), and Pseudomonas aeruginosa (1) were found in different samples. As the study was carried out during the COVID-19 pandemic, we have found 6 cases (5.9\%) of COVID-19 positive patients. The mean of days of onset of febrile neutropenia was $2.97( \pm 1.56)$ days. Stimulators (including G-CSF and peg-interferon) were used in $54 \%$ of cases. $87(86.1 \%)$ cases of FN recovered completely and 14 (13.9\%) patients died. the mean LOS was 21.98 ( \pm 9.3$)$ days. The mean cost was $999.44( \pm 499.05)$ USD per FN episode. (Table 1) 
Table-1 : Demographic and clinical characteristics of the patients $(n=101)$

\begin{tabular}{|c|c|c|c|}
\hline Baseline characteristics & $\begin{array}{l}\text { Number of patients } \\
\qquad(\mathrm{n}=101)\end{array}$ & Baseline characteristics & $\begin{array}{l}\text { Imber of patients } \\
\qquad(\mathrm{n}=101)\end{array}$ \\
\hline Age in years & & Hypertension & $1(1 \%)$ \\
\hline Mean age $( \pm \mathrm{SD})$ & $33.49( \pm 15.79)$ years & Chronic viral hepatitis $\mathrm{C}$ & $1(1 \%)$ \\
\hline 13 to 40 & $77(76.2 \%)$ & \multicolumn{2}{|l|}{ Sample which are positive for organism } \\
\hline 41 to 60 & $16(15.8 \%)$ & Blood & $3(3 \%)$ \\
\hline 60 to 80 & $8(7.9 \%)$ & Urine & $3(3 \%)$ \\
\hline Gender & & Throat & $1(1 \%)$ \\
\hline Male & $64(63.4 \%)$ & NHL & $8(7.9 \%)$ \\
\hline Female & $37(36.6 \%)$ & \multicolumn{2}{|l|}{ RT-PCR for COVID-19 } \\
\hline Primary diagnosis- no. $(\%)$ & & Positive & $6(5.9 \%)$ \\
\hline ALL & $47(46.5 \%)$ & Days of onset of febrile neutropenia $( \pm \mathrm{SD})$ & $2.97( \pm 1.56)$ \\
\hline AML & $40(39.6 \%)$ & \multicolumn{2}{|l|}{ Stimulators-no. $(\%)$} \\
\hline $\mathrm{HL}$ & $4(4 \%)$ & G-CSF & $50(49.5 \%)$ \\
\hline CML in blast crisis & $1(1 \%)$ & Pegylated-interferon & $4(4 \%)$ \\
\hline MM & $1(1 \%)$ & None & $47(46.5 \%)$ \\
\hline Co-morbidities-no. $(\%)$ & & \multicolumn{2}{|l|}{ Outcome- no. $(\%)$} \\
\hline Diabetes mellitus & $3(3 \%)$ & Responsive & $87(86.1 \%)$ \\
\hline Ischaemic heart disease & $3(3 \%)$ & Death & $14(13.9 \%)$ \\
\hline Chronic kidney disease & $2(2 \%)$ & Mean hospital length of stay ( \pm SD)-days & $21.98( \pm 9.3)$ \\
\hline Deep vein thrombosis & $2(2 \%)$ & Mean cost $( \pm$ SD)- dollars & $999.44( \pm 499.05)$ \\
\hline
\end{tabular}

$\mathrm{SD}=$ standard deviation, $\mathrm{ALL}=$ acute lymphoblastic leukaemia, $\mathrm{AML}=$ acute myeloblastic leukaemia, NHL=non-Hodgkin's lymphoma, $\mathrm{HL}=$ Hodgkin's lymphoma, $\mathrm{CML}=$ chronic myelod leukaemia, $\mathrm{MM}=$ multiple myeloma, $\mathrm{GCSF}=$ granulocyte colony stimulating factor.

Having co-morbidities was significantly associated with death (RR 3.55, 95\% CI: 1.28-9.82, p-value 0.041). Having COVID-19 was significantly associated with death (RR 4.32,95\% CI: 1.63-11.44, p-value 0.003). (Table 2)

Table 2: Association of co-morbidities and COVID-19 with the outcome of patients with febrile neutropenia ( $n=101)$

\begin{tabular}{lccccc}
\hline Characteristics & Death & Responsive & RR & $95 \%$ CI & p-value \\
\hline Co-morbidities & 3 & 4 & 3.55 & $1.28-9.82$ & $0.01^{*}$ \\
RT-PCR for COVID-19 & 3 & 3 & 4.32 & $1.63-11.44$ & $0.003^{*}$ \\
\hline
\end{tabular}

$\mathrm{RR}=$ Risk ratio $\mathrm{CI}=$ confidence interval; ${ }^{*}$ Fisher's exact test

Pearson correlation analysis was carried out to find out if there is a relationship between hospital length of stay (LOS) and cost. The assumptions of normality, linearity, and homoscedasticity were checked, with no violations found. There was a strong positive significant correlation between LOS and $\operatorname{cost}(r=.726, n=99, p<.001)$ with an increase in
LOS is associated with higher cost. This relationship can account for $52.7 \%$ of variation of scores $\left(\mathrm{R}^{2}=.527\right)$.

The association of malignancy type with cost was evaluated. Patients will AML had a significantly higher cost than patients with other haematological malignancies. (Table 3 and Table 4) 
Table 3 : Descriptive analysis of the cost $(n=101)$

\begin{tabular}{|c|c|c|c|}
\hline \multirow[t]{2}{*}{ Variables } & \multirow[t]{2}{*}{ No. $(\%)$} & \multicolumn{2}{|c|}{$\begin{array}{c}\text { Hospital cost } \\
\text { Per episode, US\$ }\end{array}$} \\
\hline & & Mean $( \pm 95 \% \mathrm{CI})$ & $\mathrm{p}$-value \\
\hline All subjects & $101(100 \%)$ & $999( \pm 499)$ & \\
\hline \multicolumn{4}{|l|}{ Age in years } \\
\hline $13-40$ & $77(76.2 \%)$ & $1020( \pm 463)$ & \\
\hline $41-60$ & $16(15.8 \%)$ & $949( \pm 520)$ & 0.735@ \\
\hline $61-80$ & $8(7.9 \%)$ & $898( \pm 792)$ & \\
\hline \multicolumn{4}{|l|}{ Gender } \\
\hline Male & $64(63.4 \%)$ & $1018( \pm 530)$ & $0.263^{\#}$ \\
\hline Female & $37(36.6))$ & $967( \pm 445)$ & \\
\hline \multicolumn{4}{|c|}{ Type of malignancy } \\
\hline ALL & $47(46.5 \%)$ & $1043( \pm 511)$ & \\
\hline AML & $40(39.6 \%)$ & $1093( \pm 465)$ & $0.004 @$ \\
\hline NHLHL & $8(7.9 \%) 4(4 \%)$ & $559( \pm 298) 452( \pm 369)$ & \\
\hline \multicolumn{4}{|c|}{ Therapeutic stimulators } \\
\hline GCSF & $50(49.5 \%$ & $985( \pm 509)$ & \\
\hline Peg-interferon & $4(4 \%)$ & $1218( \pm 640)$ & 0.670@ \\
\hline No stimulator & $47(46.5 \%)$ & $995( \pm 483)$ & \\
\hline
\end{tabular}

$\mathrm{CI}=$ Confidence interval; ${ }^{\circledR} \mathrm{p}$ value from ANOVA test; ${ }^{*} \mathrm{p}$ value from two-sample $\mathrm{t}$-test, assumed equal variance

Table-4: Comparison of costs among subsets of variables identified in univariate analysis $(n=101)$

\begin{tabular}{|c|c|c|c|c|}
\hline \multirow[t]{2}{*}{ Variables } & \multirow[t]{2}{*}{ Reference (r) } & \multicolumn{2}{|c|}{ Comparator (c) } & \multirow[t]{2}{*}{ Cost US\$ } \\
\hline & & Mean difference & p-value ${ }^{@}$ & \\
\hline \multirow[t]{3}{*}{ Type of malignancy } & AML & ALL & 50 & 1.00 \\
\hline & & $\mathrm{HL}$ & 640 & .071 \\
\hline & & $\mathrm{NHL}$ & 3534 & $.028 *$ \\
\hline
\end{tabular}

*Significant at $\alpha=0.05$ after Bonferroni correction; @ Conducted by using Scheffe’s test with Bonferroni correction

The LOS (coefficient $=41.37,95 \%$ CI: $33.243-49.51, \mathrm{p}<0.001$ ) was significantly associated with higher cost. This multivariate model for the cost had an adjusted $\mathrm{R}^{2}$ of $0.560(\mathrm{p}<0.001)$. (Table 5)

Table-5 : Factors associated with higher cost in a regression model $(n=101)^{a}$

\begin{tabular}{|c|c|c|c|c|c|c|}
\hline \multirow[t]{2}{*}{ Variables $^{b}$} & \multirow{2}{*}{$\begin{array}{l}\text { Unstandardized } \\
\text { coefficient (B) }\end{array}$} & \multicolumn{2}{|c|}{$95 \% \mathrm{CI}$ for B } & \multirow{2}{*}{$\begin{array}{l}\text { Standard error } \\
\text { coefficient (B) }\end{array}$} & \multirow[t]{2}{*}{ Standardized } & \multirow[t]{2}{*}{ p-value } \\
\hline & & Lower bound & Upper bound & & & \\
\hline AML & -9.898 & -74.353 & 54.557 & 32.471 & -.022 & .761 \\
\hline Length of stay & 41.374 & 33.243 & 49.505 & 4.096 & .745 & $<0.001$ \\
\hline
\end{tabular}

$\mathrm{a}=$ Adjusted $\mathrm{R}^{2}=0.560, \mathrm{p}<0.001 ; \mathrm{b}=$ Only clinically relevant variables that were statstically significant at $\mathrm{p}$-value of 0.05 in the univariate analysis were included in the regression model; $\mathrm{c}=$ Bolded $\mathrm{p}$ are statistically significant 


\section{Discussion:}

Febrile neutropenia is an independent risk factor for mortality and morbidity in cancer patients, especially in haematogical malignancies. ${ }^{13,14,15}$ This present study was carried out among the hospitalized patients in National Institute of Cancer Research and Hospital, Dhaka, Bangladesh with febrile neutropenia to see the response, total out-of-pocket patient cost, and factors associated with higher cost. A higher number of male gender (63.4\%)was found here with a mean age of $33.49( \pm 15.79)$ years, which slightly has differed from that of the study of Singapore where the mean age was 54.8 years and only $37.9 \%$ were male. ${ }^{3}$ Overall in-hospital mortality was found $13.9 \%$ which is higher than that of the study in Turkey 16,17 and study from Iran ${ }^{18}$ where mortality was $10.3 \%$ and $5.3 \%$ respectively, but it was similar to that of Indian studies $13.5 \%{ }^{19}$

Among the malignancies, the most frequent one was ALL (46.5\%) and the least ones were MM and CML in blast crisis. However, a study from the southern part of India showed that AML was more frequent in hospitalized febrile neutropenic patients. ${ }^{19}$ Culture positivity (blood, urine, throat swab) was found only in $7 \%$ of patients whereas $29.62 \%$ culture-positive cases were found in an Indian study. This difference could be due to prophylactic antibiotics, a faulty technique of collection procedure, presence of atypical organisms. ${ }^{3,17}$ As the study was conducted during the period of the COVID-19 pandemic the RT-PCR for COVID-19 was done in patients where clinical suspicion of COVID-19 was present and we found $6(5.9 \%)$ positive cases and it was statistically significant in comparison to the outcome. A study from Egypt had shown 29.16\% COVID-19 positive cases with an increased number of unfavorable outcomes in FN patients. ${ }^{20}$ Associated co-morbidities including diabetes, hypertension, IHD, CKD, and chronic viral hepatitis C showed an increased number of unfavorable outcome. This scenario was common to the other studies from Singapore ${ }^{3}$ and $\operatorname{Iran}^{17}$.

The length of stay in the hospital was $21.98( \pm 9.3)$ days in the current study. However, the LOS in NHL patients was about eight days in a study from $\mathrm{USA}^{21}$ and 16 days in a Brazilian study. ${ }^{22}$ LOS is associated with a higher economic burden and also unfavorable outcome. . $^{3,4,21,22}$

The total out-of-pocket patient cost was US\$999.4 ( \pm 499.05$)$ which is much lower than that of Singapore $(\mathrm{US} \$ 2230)^{3}$ and USA $(\$ 37555)^{21}$.

The limitation of our study is that it is an observational study. We cannot|be certain that we have identified all potential confounding factors. However, the assessment of independent variaples by a research group not involved in patient care and the use of a prospective design with an objective endpoint contributed to the methodological strength of this study.

\section{Conclusion:}

A longer length of hospital stay was associated with a higher out-of-pocket patient expenditure. Associated co-morbidities and COVID-19 infection showed a bad prognosis in respect of clinical outcome. The study identified factors associated with a higher financial burden on patients despite government subsidies. These results may be used for further economic evaluation to develop appropriate strategies to reduce the cost of FN on cancer patients.

\section{References:}

1. Li S, Liu J, Bowers C, Garawin TAFS, Kim C, Bensink ME, et al. Febrile neutropenia-related care and associated costs in elderly patients with breast cancer, lung cancer, or nonHodgkin lymphoma. Support Care Cancer. 2020;28(1):113122. doi: 10.1007/s00520-019-04795-0.

2. Wang XJ, Lopez SE, Chan A. Economic burden of chemotherapy-induced febrile neutropenia in patients with lymphoma: a systematic review. Crit Rev Oncol Hematol. 2015;94(2):201-12. doi: 10.1016/j.critrevonc.2014.12.011.

3. Wang XJ, Wong M, Hsu LY, Chan A. Costs associated with febrile neutropenia in solid tumor and lymphoma patients an observational study in Singapore. BMC Health Serv Res. 2014;14:434. doi: 10.1186/1472-6963-14-434.

4. Dulisse B, Li X, Gayle JA, Barron RL, Ernst FR, Rothman $\mathrm{KJ}$, et al. A retrospective study of the clinical and economic burden during hospitalizations among cancer patients with febrile neutropenia. J Med Econ. 2013;16(6):720-35. doi: $10.3111 / 13696998.2013 .782034$.

5. Taplitz RA, Kennedy EB, Bow EJ, Crews J, Gleason C, Hawley DK, et al. Antimicrobial Prophylaxis for Adult Patients With Cancer-Related Immunosuppression; ASCO and IDSA Clinical Practise Guideline Update. J Clin oncol. 2018. 36(30):3043-3054. doi: 10.1200/JCO.18.00374

6. Poon LM, Jin J, Chee YL, Ding Y, Lee YM, Chng WJ, et al. Risk factors for adverse outcomes and multidrug-resistant Gram-negative bacteraemia in haematology patients with febrile neutropenia in a Singaporean university hospital. Singapore Med J. 2012, 53: 720-725.

7. Lyman GH, Morrison VA, Dale DC, Crawford J, Delgado DJ, Fridman M. Risk of febrile neutropenia among patients with intermediate-grade non-Hodgkin's lymphoma receiving CHOP chemotherapy. Leukemia \& lymphoma. 2003, 44: 2069-2076. doi:10.1080/1042819031000119262.

8. Gustinetti G, Mikulska M. Bloodstream infections in neutropenic cancer patients: A practical update. Virulence. 2016;7(3):280-297. doi:10.1080/21505594.2016.1156821 
9. Michels SL, Barron RL, Reynolds MW, Tomic KS, Yu J, Lyman JH. Costs associated with febrile neutropenia in the US. PharmacoEconomics. 2012, 30: 809-823. doi:10.2165/ 11592980-000000000-00000

10. Ihbe-Heffinger A, Paessens BJ, von Schilling C, Shlaen M, Gottschalk N, Berger K, et al. Management of febrile neutropenia-a German prospective hospital cost analysis in lymphoproliferative disorders, non-small cell lung cancer, and primary breast cancer. Onkologie. 2011, 34: 241-246. doi:10.1159/00032771

11. Soares M, Caruso P, Silva E, Teles JM, Lobo SM, Friedman $\mathrm{G}$, et al. Brazilian Research in Intensive Care Network (BRICNet) Characteristics and outcomes of patients with cancer requiring admission to intensive care units: a prospective multicenter study. Crit Care Med. 2010;38:915. doi: 10.1097/CCM.0b013e3181c0349e.

12. Oeyen SG, Benoit DD, Annemans L, Depuydt PO, van Belle SJ, Troisi RI, Noens LA, et al. Long-term outcomes and quality of life in critically ill patients with hematological or solid malignancies: a single center study. Intensive Care Med. 2013;39:889-898. doi: 10.1007/s00134-012-2791-x.

13. Lee DS, Suh GY, Ryu JA, Chung CR, Yang JH, Park CM, et al. Effect of early intervention on long-term outcomes of critically ill cancer patients admitted to ICUs. Crit Care Med. 2015;43:1439-1448. doi: 10.1097/CCM.0000000 000000989.

14. Klastersky J, de Naurois J, Rolston K, Rapoport B, Maschmeyer G, Aapro M, et al. Management of febrile neutropaenia: ESMO Clinical Practice Guidelines. Annals of Oncology 27 (Supplement 5): v111-v118, 2016 doi:10.1093/ annonc/mdw325

15. Zhou YP, Jin J, Ding Y, Chee YL, Koh LP, Chng WJ, et al. Direct costs associated with febrile neutropenia in inpatients with hematological diseases in Singapore. Supportive Care in Cancer. 2014, 22: 1447-1451. 10.1007/s00520-013-20555 .

16. Kuderer NM, Dale DC, Crawford J, Cosler LE, Lyman GH. Mortality, morbidity, and cost associated with febrile neutropenia in adult cancer patients. Cancer. 2006;106:225866. $10.1002 /$ cncr. 21847

17. Görük M, Dal MS, Dal T, Karakus A, Tekin R, Özcan N, et al. Evaluation of febrile neutropenic patients hospitalized in a hematology clinic. Asian Pacific Journal of Tropical Biomedicine.2015;5(12):1051-1054. https://doi.org/10.1016/ j.apjtb.2015.09.014.

18. Lyman GH, Michels SL, Reynolds MW, Barron R, Tomic $\mathrm{KS}, \mathrm{Yu}$ J. Risk of mortality in patients with cancer who experience febrile neutropenia. Cancer. 2010;116(23):555563. 10.1002/cner.25332.

19. Lakshmaiah KC, Malabagi AS, Govindbabu, Shetty R, Sinha M, Jayashree RS. febrile neutropenia in hematological malignancies: clinical and microbiological profile and outcome in high risk patients. J Lab Physicians. 2015;7(2):116-20. doi: 10.4103/0974-2727.163126.

20. Hamdy R, El Mahallawy H, Ebeid E. COVID -19 infection in febrile Neutropenic paediatric hematology oncology patients. pediar blood cancer. 2021;68(2):e28765. doi: $10.1002 /$ pbc. 28765 .

21. Kawatkar AA, Farias AJ, Chao C, Chen W, Barron R, Vogl FD et al. Hospitalizations, outcomes, and management costs of febrile neutropenia in patients from a managed care population. Support Care Cancer. 2017;25(9):2787-2795. doi:10.1007/s00520-017-3692-x

22. Rosa RG, Goldani LZ. Factors associated with hospital length of stay among cancer patients with febrile neutropenia. PLoS One. 2014;9(10):e108969. doi:10.1371/journal.pone.0108969 